\title{
Huge borderline phyllodes breast tumor with repeated recurrences and progression toward more malignant phenotype: a case report and literature review
}

This article was published in the following Dove Press journal:

OncoTargets and Therapy

\section{Yining Wang* \\ Yonglin Zhang* \\ Guanglei Chen \\ Fangming Liu \\ Chao Liu \\ Tiantian Xu \\ Zhenhai Ma}

Department of Breast Disease and Reconstruction Center, Breast Cancer Key Lab of Dalian, The Second Affiliated Hospital of Dalian Medical University, Dalian, Liaoning II6027, China

*These authors contributed equally to this work
Correspondence: Zhenhai Ma Department of Breast Disease and Reconstruction Center, Breast Cancer Key Lab of Dalian, The Second Affiliated Hospital of Dalian Medical University, 467 Zhongshan Road, Dalian, Liaoning II 6027, China

Tel +86 4 I | 8467 |29|

Fax $+8641 I 84672130$

Email mazhenhai2004@I63.com
Background: Phyllodes tumor (PT) is a rare breast fibroepithelial biphasic tumor composed of stromal and epithelial components. The patients suffering from this disease present with a large, round, mobile, fast-growing lump, and the giant PT of more than $10 \mathrm{~cm}$ in diameter is so uncommon. Surgery is regarded as the primary treatment, but curative efficiency of adjuvant chemotherapy and radiotherapy is so indefinite.

Case presentation: We reported one case of a middle-aged woman with a huge borderline PT in the right breast, over $20 \mathrm{~cm}$ in size. The pathology of needle core biopsy of the lump was suggestive of PT of the borderline subgroup, and then she underwent mastectomy of the right breast. The patient had recovered well without any postoperative treatment until a local recurrence occurred 1 year after operation. The tumor was removed with lumpectomy, which was pathologically diagnosed as malignant PT. We followed up her by telephone and heard about her postoperative adjuvant radiotherapy and chemotherapy, as well as her well recovery.

Conclusion: The pathology of PT with low incidence is mostly benign, but local recurrence is common, and the histopathology progresses toward worsen trend. Besides, due to the difficulty in precise diagnosis of the borderline PTs, it is recommended that this subtype of patients should undergo total mastectomy. Although the curative effect of postoperative treatment has not been recognized internationally, patients, especially those with huge tumors, may benefit from these treatments.

Keywords: phyllodes tumor, breast neoplasms, recurrence, diagnosis, treatment

\section{Introduction}

Breast phyllodes tumors (PTs), composed of stromal and epithelial elements, are rare biphasic fibroepithelial tumors, with an incidence of about 2.1 per million women, ${ }^{1}$ accounting for $0.3 \%-1 \%$ of breast neoplasms. ${ }^{2}$ Breast PTs, first named by Johannes Muller, have numerous synonyms, such as cystosarcoma phyllodes, adenomatous myxoma, and pseudosarcoma adenoma. ${ }^{3}$ WHO decided to use the term "phyllodes tumor" to name this disease formally in 2003. It usually occurs in middle-aged women mostly (age, $35-55$ years). ${ }^{4}$ Clinically, the variable tumor size is $4-7 \mathrm{~cm}$ on average, ${ }^{5}$ but about one-fifth of the PTs are called giant PT due to the uncommon diameter of more than $10 \mathrm{~cm} .{ }^{6}$ Depending on the histopathological features, PTs are categorized into three grades with different proportions, benign (60\%-75\%), borderline $(13 \%-26 \%)$, and malignant (10\%-20\%). ${ }^{7}$ Patients suffering from PTs have no specific clinical manifestations, and it is difficult to distinguish benign subgroup from borderline and malignant subgroups. Lymph node metastasis is rare, and the metastatic path mainly 
relies on the blood. Surgical removal is the primary treatment for PT, given that adjuvant treatments play a poorly efficient role. Here, we report an uncommon case of a female patient with a huge breast borderline PT and review literature about PTs.

\section{Case report}

In April 2016, a 44-year-old premenopausal woman was admitted to the Breast Surgery Department, the Second Hospital of Dalian Medical University, with a 12-month history of a huge lump in the right breast. Initially, the patient just had a small fist-sized lump in the right breast, without any pain or discomfort. It grew so slowly that she did not pay much attention on it. Then, the lump started to grow rapidly and became very large within 2 months, and her right breast was entirely covered with a 8 -inch ball-sized mass. The breast skin appeared dark and had ulceration.

The patient had undergone breast lump resection twice in 2001 and 2008, and both pathological diagnoses were benign PT. The patient had no history of cardiovascular or respiratory disease. Moreover, she had no family history of breast cancer.

Physical examination revealed that the left breast was normal, without any palpable lump. The right breast was obviously large, nearly $25 \times 25 \mathrm{~cm}$ in size, with a circumference of nearly $80 \mathrm{~cm}$. The skin on the surface of the lump was dark, with ulceration area of $7 \times 5 \mathrm{~cm}$ and without bleeding or discharge (Figure 1A and B). On palpation, the size of the lump was $18 \times 20 \mathrm{~cm}$, hard with local tenderness and poor mobility. Axillary lymph nodes were not palpable. Mammography showed a huge right breast, about $23 \times 23$ $\mathrm{cm}$, with dermal ulceration around nipple (Figure $2 \mathrm{~A}$ and $\mathrm{B}$ ).
Ultrasonoscopy showed the right mammary gland that was enlarged obviously, with inset showing echo intensity disorder and blood flow signal probed (Figure 2C). Several hypoechoic focuses were seen on the area of right axilla, of which the largest was $1.5 \times 0.9 \mathrm{~cm}$ in size. The left breast and axilla had no abnormal signal. Biochemical examination revealed no significant abnormalities. The chest computed tomography (CT) revealed that the lump had not broken into the chest cavity, and the lungs were normal (Figure 2D). The patient's other relevant examinations such as the abdomen $\mathrm{CT}$, the brain $\mathrm{CT}$, and the bone ECT were also normal.

Needle core biopsy of the breast lump was suggestive of PT of the borderline subgroup. Then, the patient underwent mastectomy of the right breast (Figure 3) and sentinel lymph node biopsy. During surgery, surgeons detected that the pectoralis major was invaded, and so the partial muscle adhered to the tumor was resected. The intraoperative frozen section showed no metastatic cancer cell in sentinel lymph nodes. Finally, the latissimus dorsi muscle flap was graft to remedy for the tissular defect on the chest. Postoperative treatment was uneventful, and she was discharged after 6 days.

The cut surface demonstrated a leaf-like pattern. The scope of dermatic ulceration or necrosis was $13 \times 10 \mathrm{~cm}$. Postoperative paraffin-based histopathology showed fast cellular proliferation, mitosis about $9 / 10$ high-power fields (HPFs) (Figure 4A and B). The tumor did not invade the skin. Immunohistochemistry (IHC) was as follows: spindle cells AE1/AE3, smooth muscle actin (SMA) (+), Desmin (-), CD34 partial (+), BCL-2 (-), p53 partial (+), ki-67 15\%, tumor cells, estrogen receptor (ER) $<1 \%$ weakly positive, progesterone receptor (PR) $<1 \%$ weakly positive, and Ki67 $40 \%$ (Figure 4C-J).
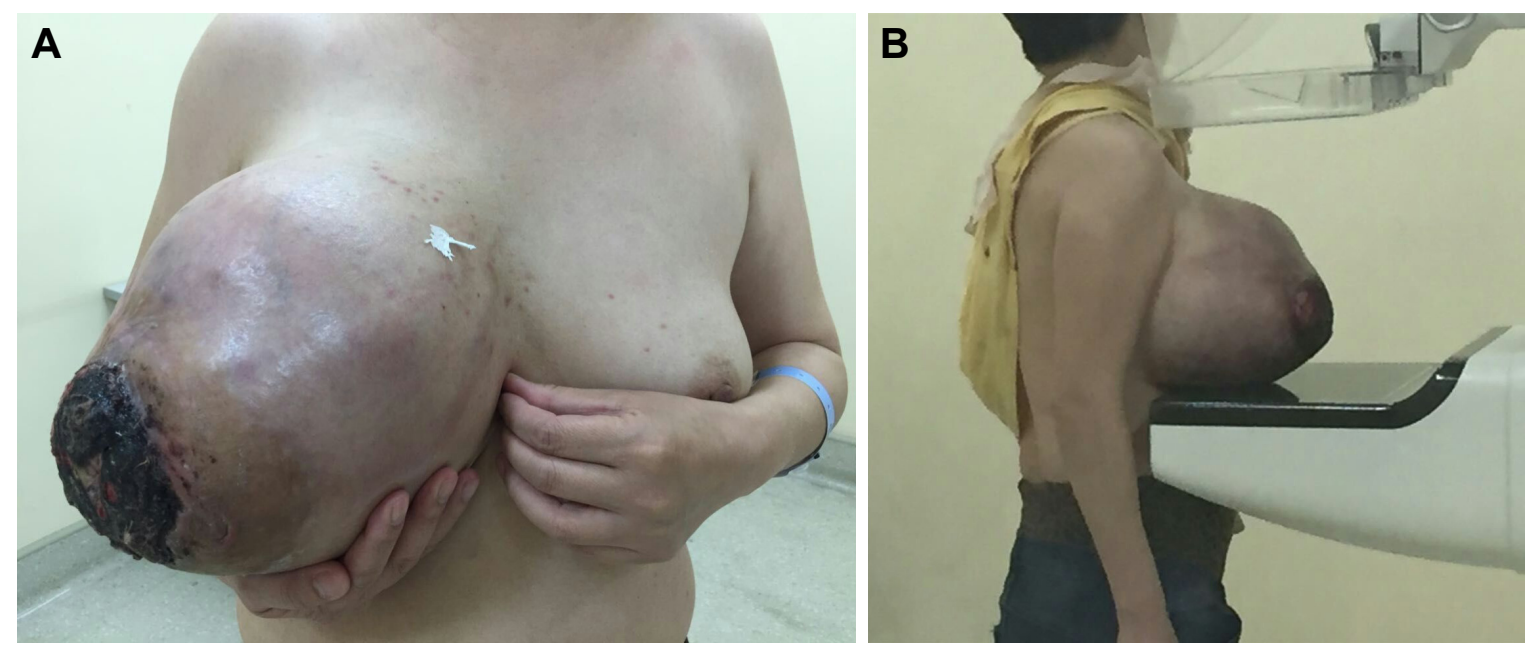

Figure I A huge borderline phyllodes tumor in the right breast of a 44 -year-old woman: front image (A) and lateral image (B). 

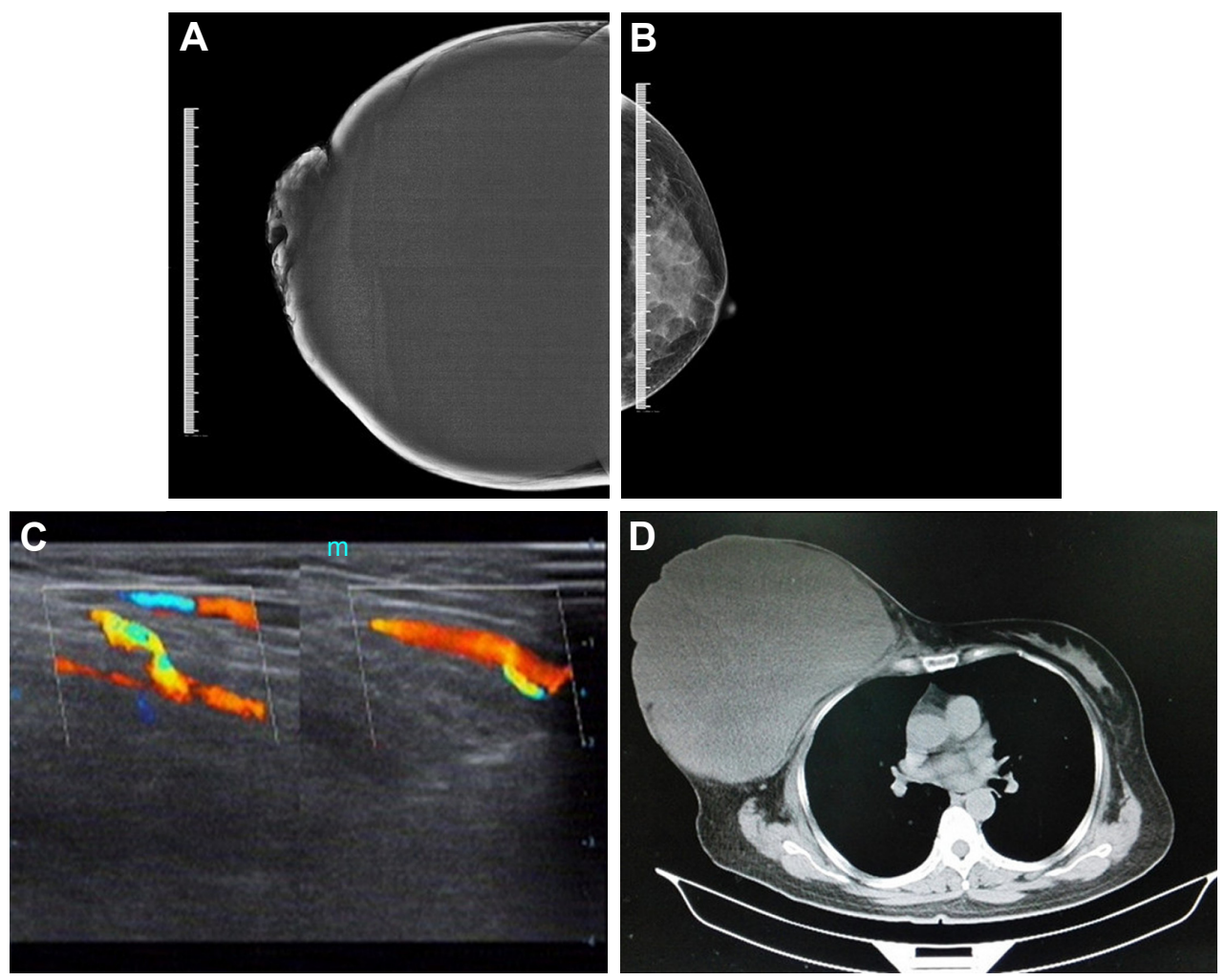

Figure 2 The images of imaging examination.

Notes: (A and B) Mammography (CC) showing a huge right breast, about $23 \times 23 \mathrm{~cm}$ and the normal left breast. (C) Ultrasonography of the right breast showing enlargement obviously; inset, echo intensity disorder and a little blood flow signal. (D) The CT of right breast showing the mass not invading chest muscle or breaking into the chest cavity.

Abbreviations: CC, craniocaudal; CT, computed tomography.

The patient had recovered well after the surgery until March 2017. The patient came to our hospital again because of a local recurrence. Her palpation and imaging examinations indicated three large masses on the right chest, the largest one of about $6.7 \times 4.0 \mathrm{~cm}$ (Figure $5 \mathrm{~A}-\mathrm{C}$ ). Then, she had lumpectomy, and the tumor was diagnosed as malignant

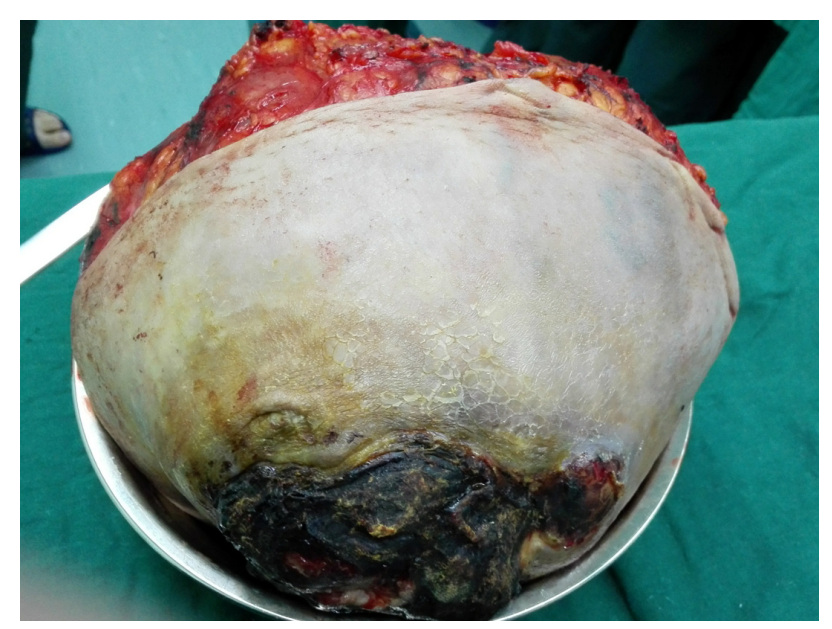

Figure 3 The resected phyllodes tumor measuring $22 \times 17 \times 14 \mathrm{~cm}$ (diameter of the dressing bowl, $16 \mathrm{~cm}$ ).
PT (Figure 5D). After the second surgery, we followed up her by telephone, and knew that she had underwent radiotherapy and chemotherapy. Up until now (February 2018), she is still alive and undergoing chemotherapy.

\section{Discussion}

Currently, although a lot of research studies focused on breast PTs, mechanisms and causes of PTs are still far from being clarified. Tan et $\mathrm{al}^{8}$ reported that the mutation in MED12, RARA, FLNA, SETD2, and KMT2D was observed in PT, suggesting that they may play important roles in PTs tumorigenesis and development. One study by Sapino et $\mathrm{al}^{9}$ showed that ER- $\beta$ with high expression in elderly patients was considered as an independent factor, and pregnancy status and a high level of estrogen were also related to this disease. Gong et al ${ }^{10}$ studied biological mechanisms of malignant transformation, concluding that miR-21 may drive the progression, and $\alpha$-SMA and miR-21, as independent prognostic markers, had more predictive value than histologic classification. Hodges et al ${ }^{11}$ suggested that some tumors showed the characteristics of both fibroadenoma and PTs, and the deletion or amplification of some allele led to the 

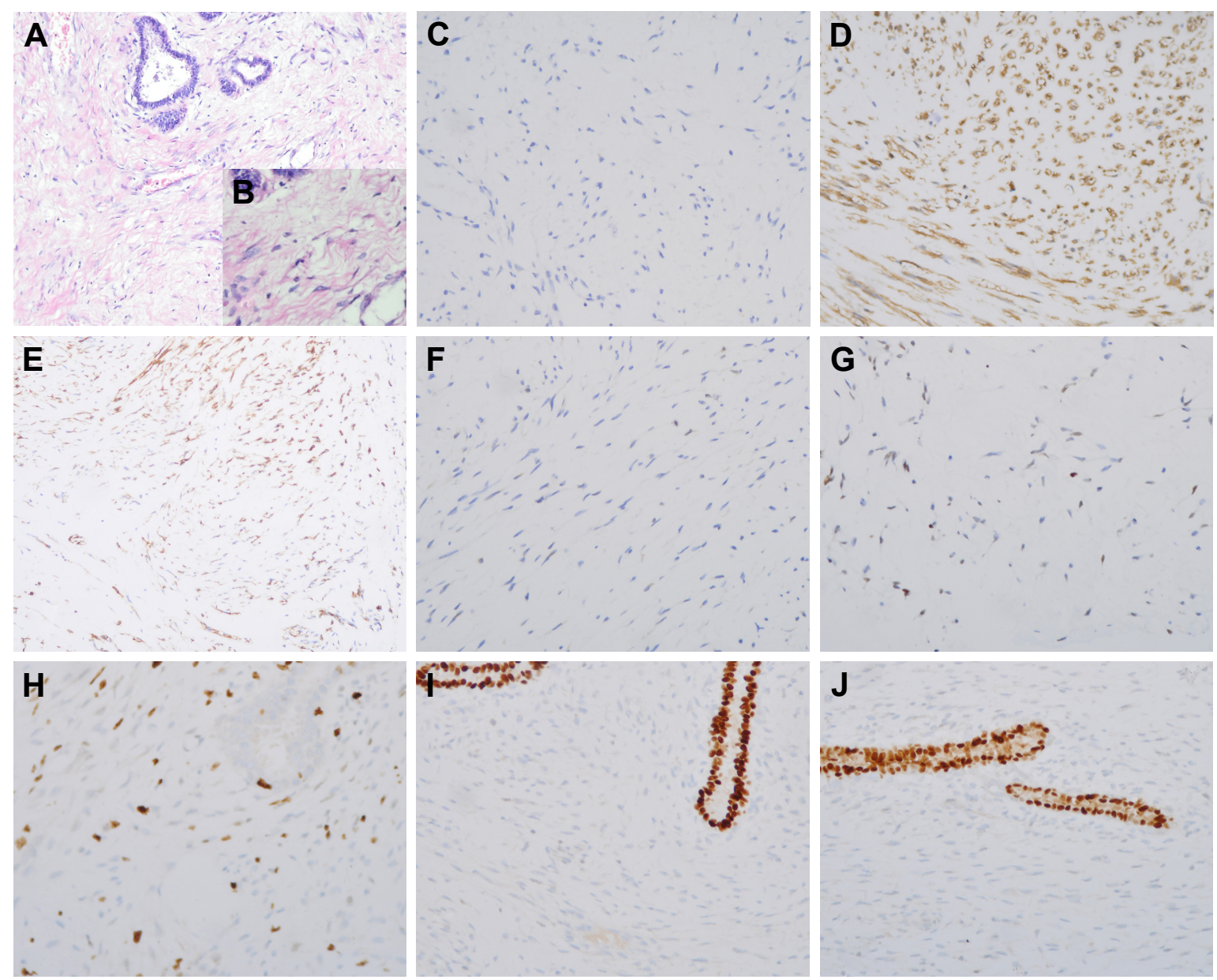

Figure 4 The tissue section showing borderline phyllodes tumor with mucoid degeneration and some areas abounded in cell: (A) I00x and (B) 200x. IHC results of (C) AEI/AE3, (D) SMA, (E) CD34, (F) BCL-2, (G) P53, (H) ki67, (I) ER, and (J) PR.

Abbreviations: IHC, immunohistochemistry; SMA, smooth muscle actin; ER, estrogen receptor; PR, progesterone receptor.

transformation of fibroadenoma into PTs. Another research study reported a higher risk of PTs in unmarried, infertile, and postmenopausal women, as well as in women using oral contraceptives at childbearing age. ${ }^{12}$

Patients suffering from breast PTs usually have nondistinctive symptoms at the beginning, and long medical history ranged from several months to years. ${ }^{13}$ Yet, only a small number of patients consulted doctors because of rapidly increasing tumors. The tumor usually exists in a unilateral breast with the characteristics of hard, clear boundary, oval or phyllodes shape, good tumor mobility, and non-adherence to skin. Huge mass may cause ulcerated, thinned, and tightened skin. The lymph node is involved rarely, and the most common metastasis path is through hematogenous channels, mainly to the lung, the pleura, and the bone. ${ }^{14}$ The tumor with distant metastasis is usually characterized by large mass, invasive growth, obvious hyperplasia of interstitial element, and abundant mitotic activities. ${ }^{15}$
Due to the lack of typical clinical symptoms and pathological characteristics that can distinguish fibroadenoma, the misdiagnosis rate is high. To diagnose the PTs accurately, it is necessary to find both epithelium and stoma in tissue specimens. ${ }^{16}$ The stromal cell components affect the pathological behavior of PTs. WHO classification of breast tumor in 2012 recommended that the PTs should be classified into three subgroups based on the stromal cellularity, stromal atypia, stromal overgrowth, mitosis, and tumor margins. ${ }^{17}$ Histologically, benign PTs have consistent nuclear morphometry of interstitial nucleus with less than 5 mitoses per $10 \mathrm{HPFs}$. In some areas where interstitial cells are sparse, hyalinosis or myxoid degeneration can be observed. Malignant PTs reveal the characteristics of nuclear pleomorphism, excessive growth of interstitial cells, and invasive margins, with mitosis more than 10/10 HPFs. Sometimes histological serialities make it difficult to exactly define the grade of tumors. 

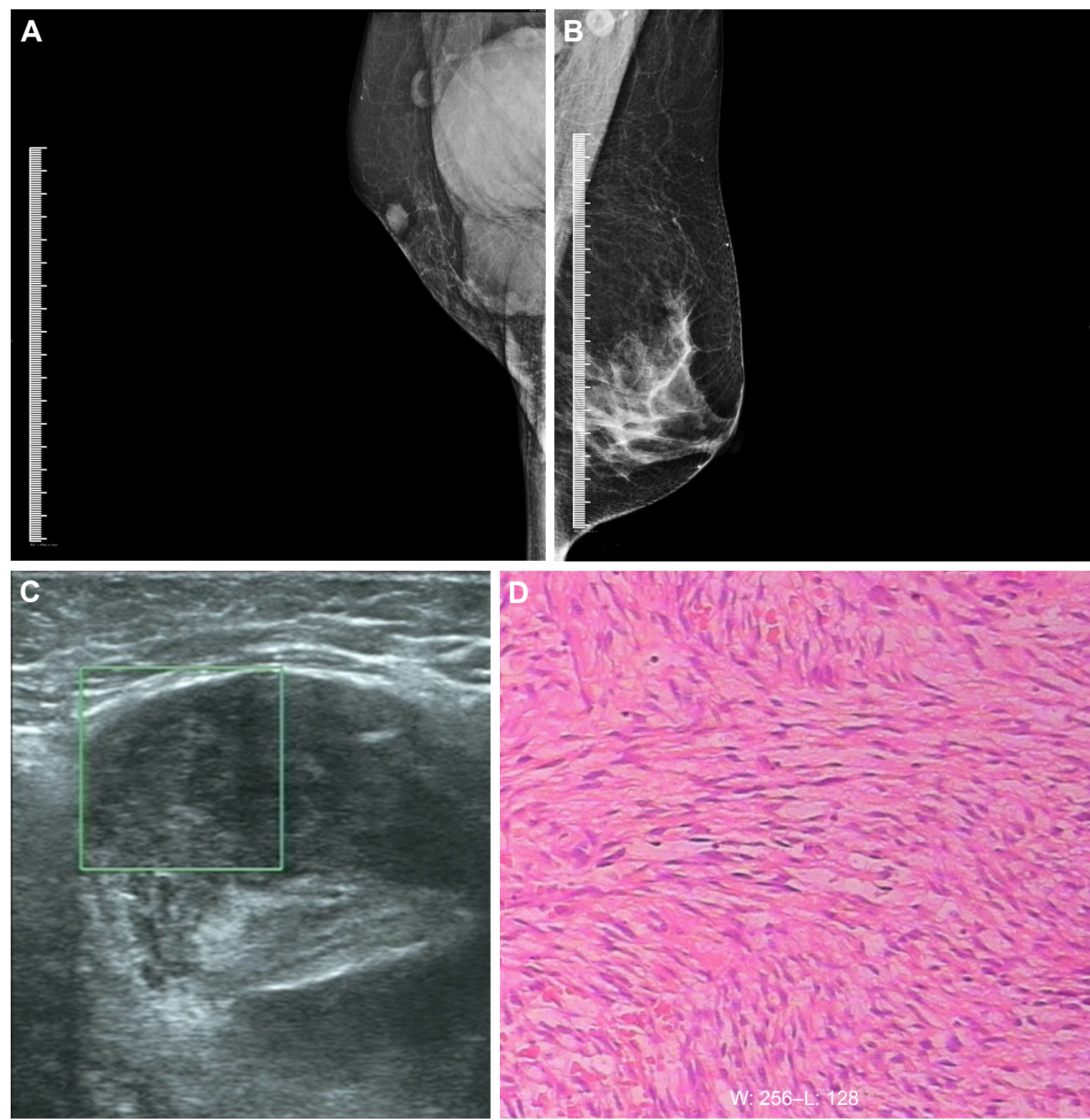

Figure $\mathbf{5}$ The examination images and pathology of the recurrent tumors.

Notes: (A and B) Mammography (MLO) showing the large tumors on the right chest and the normal left breast. (C) Ultrasonography of the right chest showing the largest tumor about $6.7 \times 4.0 \mathrm{~cm}$. (D) The tissue section showing spindle-shaped tumor cells that were arranged in bundles or wheels, and mitoses were obvious (200×).

Abbreviation: MLO, mediolateral oblique.

Preoperative diagnosis of breast PT is uneasy. Ultrasound and mammography showed no specific images, just showing large, round, and lobulated masses with clear boundary. In some mammographic images,$^{18}$ a bright halo around the tumor can be seen, due to rapidly growing tumor compressing surrounding tissues. Besides, thick calcification spots are more common rather than scattered tiny ones. The existing research studies do not confirm that magnetic resonance imaging (MRI) has advantages in diagnosis compared with the other imaging examinations. However, some studies found diagnostic differences in MRI: the enhancement curve of benign PT was almost ascending type and that of malignant tumor was flat or platform type. ${ }^{19}$ The diagnosis of PTs is mainly based on the histopathological examinations. Core needle biopsy, as a crucial method, has been widely reported that the accuracy rate was as high as $99 \%$, and the positive predictive value and negative predictive value were $93 \%$ and $83 \%$, respectively. ${ }^{20}$ However, about $39 \%$ of the patients may receive a false negative result, ${ }^{21}$ so the definite diagnosis still depends on the complete excision of the tumor, on account of histological resemblance between PTs and fibroadenoma. Cimino-Mathews et $\mathrm{al}^{22}$ broke through from immunological 
behavior, indicating that P63, P40 and cytokeratins labeled in malignant PTs, not in lower-grade PTs or fibroadenoma. Nevertheless, they still considered that the accurate diagnosis should not only rely on immunoreactivity.

The primary treatment of PT is surgery regardless of any subgroup, including various operation methods such as lumpectomy, wide local excision, and total mastectomy. In the past, surgeons generally chose simple or radical mastectomy for borderline and malignant PTs. ${ }^{23}$ The study by Hasssouna et $\mathrm{al}^{24}$ revealed that radical surgery really improved the survival and decreased the rate of local recurrence. In addition, another study by Barth et $\mathrm{al}^{25}$ showed that the prognosis of wide local excision combined with postoperative radiotherapy was equivalent to that of radical surgery. However, recently, most of the studies failed to verify advantages of extensive surgery, so surgeons proposed conservative surgery. The study by Tan et $\mathrm{al}^{26}$ indicated that the state of surgical margin was an important prognostic factor. The resection with wide margin could prevent the recurrence effectively. The National Comprehensive Cancer Network recommends that the range of negative margin should be more than $1 \mathrm{~cm}$. Based on the available clinical data, it is generally believed that the range is enough for patients with benign PTs, but those with borderline or malignant tumors should have extensive resection or even the mastectomy. Although there is no consensus for the indication of total mastectomy, some surgeons believe that this method is required for patients older than 50 years, with tumors larger than $5 \mathrm{~cm}$ or with other high-risk factors of recurrence or metastasis. ${ }^{27}$ Besides, some surgeons deemed that in view of high recurrence rate in malignant subgroup, as long as the histopathological diagnosis was malignance before or during operation, all patients should undergo total mastectomy regardless of the tumor size. ${ }^{28}$ On the basis of the reported conclusions and our own experience, we consider that total mastectomy should be feasible for patients who meet the following criteria: benign or borderline tumors more than $8 \mathrm{~cm}$ in size, positive resected margin, local recurrence more than three times, or malignant tumors. Lymph node involvement is barely in PTs, so routine axillary lymph node dissection is often unnecessary, ${ }^{29}$ unless preoperatively lymph node involvement has been detected pathologically. For those patients with palpable lymph nodes or huge breast mass, sentinel node biopsy or low-grade axillary lymph nodes dissection is recommended. ${ }^{30}$

The curative effect of postoperative comprehensive treatments such as adjuvant chemotherapy and radiotherapy against malignant PT is limited. An early study by Chaney et $\mathrm{al}^{31}$ revealed that patients suffering from borderline or malignant PTs have been profited from radiotherapy, especially those with tumors of huge size, positive margin, nuclear pleomorphism, and necrosis. Barth et $\mathrm{al}^{32}$ and Belkacémi et $\mathrm{al}^{33}$ also confirmed that postoperative radiotherapy could prolong disease-free survival and lower the risk of recurrence. However, because there are no sufficient multicenter large-scale sample studies, the evidence listed above cannot be completely relied on. Several studies showed a contradictive conclusion that postoperative chemotherapy and endocrine therapy had no significant effect on reducing the rate of recurrence or death.

The overall 5-year disease-free survival rate of PT ranged from $78 \%$ to $91 \% .{ }^{34}$ The rate of recurrence is about $10 \%-40 \%$ for all PTs patients, and malignant or borderline patients have higher rate than benign ones. Most recurrence happens within 2 years after surgery; besides, the pathology of recurrence tumors often shows a worse condition. Patients should review at least once every 6 months during the first 2 years and then once a year thereafter. Since the prognosis was closely related to the histopathological subgroup, the extent of primary surgical resection, and medical history of previous fibroadenomam, ${ }^{35}$ patients with these risk factors should have more frequent review.

\section{Conclusion}

This case report particularly presents a huge borderline PT in the right breast and postoperatively local recurrence with worse histopathology. PT is a rare breast disease but recurs easily. The tumor behavior is very difficult to predict. The primary treatment is operation, yet the efficiency of adjuvant treatment is still under investigation. For patients with invasive chest muscles, adjuvant radiotherapy may decrease the risk of local recurrence postoperatively.

\section{Acknowledgment}

This study was funded by the Natural Science Fund Project of Liaoning province (No 20170540254) and Medical Science Research Project of Dalian (No 1612019).

\section{Disclosure}

The authors report no conflicts of interest in this work.

\section{References}

1. Zhou H, Wang C, Zhang P, Wang X. A huge borderline phyllodes breast tumors. Breast J. 2014;20(6):663-665.

2. Guerrero MA, Ballard BR, Grau AM. Malignant phyllodes tumor of the breast: review of the literature and case report of stromal overgrowth. Surg Oncol. 2003;12(1):27-37. 
3. Sanguinetti A, Bistoni G, Calzolari F, et al. Cystosarcoma phyllodes with muscular and lymph node metastasis. Our experience and review of the literature. Ann Ital Chir. 2012;83(4):331-336.

4. Testori A, Meroni S, Errico V, Travaglini R, Voulaz E, Alloisio M. Huge malignant phyllodes breast tumor: a real entity in a new era of early breast cancer. World J Surg Oncol. 2015;13:81.

5. Barrio AV, Clark BD, Goldberg JI, et al. Clinicopathologic features and long-term outcomes of 293 phyllodes tumors of the breast. Ann Surg Oncol. 2007;14(10):2961-2970.

6. Mishra SP, Tiwary SK, Mishra M, Khanna AK. Phyllodes tumor of breast: a review article. ISRN Surg. 2013;2013:361469.

7. Tse GM, Niu Y, Shi HJ. Phyllodes tumor of the breast: an update. Breast Cancer. 2010;17(1):29-34.

8. Tan J, Ong CK, Lim WK, et al. Genomic landscapes of breast fibroepithelial tumors. Nat Genet. 2015;47(11):1341-1345.

9. Sapino A, Bosco M, Cassoni P, et al. Estrogen receptor-beta is expressed in stromal cells of fibroadenoma and phyllodes tumors of the breast. Mod Pathol. 2006;19(4):599-606.

10. Gong C, Nie Y, Qu S, et al. miR-21 Induces Myofibroblast Differentiation and Promotes the Malignant Progression of Breast Phyllodes Tumors. Cancer Res. 2014;74(16):4341-4352.

11. Hodges KB, Abdul-Karim FW, Wang M, et al. Evidence for transformation of fibroadenoma of the breast to malignant phyllodes tumor. Appl Immunohistochem Mol Morphol. 2009;17(4):345-350.

12. Majeski J, Stroud J. Malignant phyllodes tumors of the breast: a study in clinical practice. Int Surg. 2012;97(2):95-98.

13. Reinfuss M, Mituś J, Duda K, Stelmach A, Ryś J, Smolak K. The treatment and prognosis of patients with phyllodes tumor of the breast: an analysis of 170 cases. Cancer. 1996;77(5):910-916.

14. Holthouse DJ, Smith PA, Naunton-Morgan R, Minchin D. Cystosarcoma phyllodes: the Western Australian experience. Aust N Z J Surg. 1999;69(9):635-638.

15. Barrio AV, Clark BD, Goldberg JI, et al. Clinicopathologic features and long-term outcomes of 293 phyllodes tumors of the breast. Ann Surg Oncol. 2007;14(10):2961-2970.

16. Sugie T, Takeuchi E, Kunishima F, Yotsumoto F, Kono Y. A case of ductal carcinoma with squamous differentiation in malignant phyllodes tumor. Breast Cancer. 2007;14(3):327-332.

17. Lakhani SR, Ellis IO, Schnitt SJ. WHO Classification of Tumours of the Breast. 4th ed. Lyon: IARC; 2012:143-147.

18. Cosmacini P, Veronesi P, Zurrida S, Bartoli C, Ferranti C, Coopmans De Yoldi G. Mammography in the diagnosis of phyllodes tumors of the breast. Analysis of 99 cases. Radiol Med. 1991;82(1-2):52-55. Italian.

19. Tse GMK, Cheung HS, Pang LM, et al. Characterization of Lesions of the Breast with Proton MR Spectroscopy: Comparison of Carcinomas, Benign Lesions, and Phyllodes Tumors. AJR Am J Roentgenol. 2003;181(5):1267-1272.
20. Komenaka IK, El-Tamer M, Pile-Spellman E, Hibshoosh H. Core needle biopsy as a diagnostic tool to differentiate phyllodes tumor from fibroadenoma. Arch Surg. 2003;138(9):987-990.

21. Dillon MF, Quinn CM, McDermott EW, O’Doherty A, O'Higgins N, Hill AD. Needle core biopsy in the diagnosis of phyllodes neoplasm. Surgery. 2006;140(5):779-784.

22. Cimino-Mathews A, Sharma R, Illei PB, Vang R, Argani P. A Subset of Malignant Phyllodes Tumors Express p63 and p40. Am J Surg Pathol. 2014;38(12):1689-1696.

23. Mallick S, Joshi NP, Roy S, et al. Malignant and borderline phyllodes tumor of breast treated with a multi-modality approach in a tertiary cancer care centre in North India. South Asian J Cancer. 2016;5(1):1-3.

24. Ben Hassouna J, Damak T, Gamoudi A, et al. Phyllodes tumors of the breast: a case series of 106 patients. Am J Surg. 2006;192(2): 141-147.

25. Barth RJ Jr, Wells WA, Mitchell SE, Cole BF. A prospective, multiinstitutional study of adjuvant radiotherapy after resection of malignant phyllodes tumors. Ann Surg Oncol. 2009;16(8):2288-2294.

26. Tan PH, Thike AA, Tan WJ, et al; Phyllodes Tumour Network Singapore. Predicting clinical behaviour of breast phyllodes tumours: a nomogram based on histological criteria and surgical margins. J Clin Pathol. 2012;65(1):69-76.

27. Zhao J, Gao Z, Qx L. Analysis of diagnosis and treatment of breast phyllodes tumor. Clin M\&M. 2014;27(2):7-10. Chinese.

28. Guillot E, Couturaud B, Reyal F, et al; Breast Cancer Study Group of the Institut Curie. Management of phyllodes breast tumors. Breast J. 2011;17(2):129-137.

29. Lenhard MS, Kahlert S, Himsl I, Ditsch N, Untch M, Bauerfeind I. Phyllodes tumour of the breast: clinical follow-up of 33 cases of this rare disease. Eur J Obstet Gynecol Reprod Biol. 2008;138(2):217-221.

30. Parker SJ, Harries SA. Phyllodes tumours. Postgrad Med J. 2001; 77(909):428-435.

31. Chaney AW, Pollack A, McNeese MD, Zagars GK. Adjuvant radiotherapy for phyllodes tumor of breast. Radiat Oncol Investig. 1998;6(6): 264-267.

32. Barth RJ Jr, Wells WA, Mitchell SE, Cole BF. A prospective, multiinstitutional study of adjuvant radiotherapy after resection of malignant phyllodes tumors. Ann Surg Oncol. 2009;16(8):2288-2294.

33. Belkacémi Y, Bousquet G, Marsiglia H, et al. Phyllodes tumor of the breast. Int J Radiat Oncol Biol Phys. 2008;70(2):492-500.

34. Zayen S, Amouri H, Dhouib M, Trigui D, Ayed BB, Guermazi M. Giant phyllodes tumor of the breast: Consequence of carelessness. Acta Oncol. 2011;50(3):468-470.

35. Wang H, Wang X, Wang CF. Prognostic analysis of benign, borderline and malignant phyllodes tumors of the breast. Chin J Oncol. 2015; 37(12):923-927.
OncoTargets and Therapy

\section{Publish your work in this journal}

OncoTargets and Therapy is an international, peer-reviewed, open access journal focusing on the pathological basis of all cancers, potential targets for therapy and treatment protocols employed to improve the management of cancer patients. The journal also focuses on the impact of management programs and new therapeutic agents and protocols on

\section{Dovepress}

patient perspectives such as quality of life, adherence and satisfaction. The manuscript management system is completely online and includes a very quick and fair peer-review system, which is all easy to use. Visit http://www.dovepress.com/testimonials.php to read real quotes from published authors. 